\title{
Acquisition and extinction of somatic symptoms in response to odours: a pavlovian paradigm relevant to multiple chemical sensitivity
}

Omer Van den Bergh, Kris Stegen, Ilse Van Diest, Cathy Raes, Peter Stulens, Paul Eelen, Hendrik Veulemans, Karel P Van de Woestijne, Benoit Nemery

\begin{abstract}
Objectives-Multiple chemical sensitivity is a poorly understood syndrome in which various symptoms are triggered by chemically unrelated, but often odorous substances, at doses below those known to be harmful. This study focuses on the process of pavlovian acquisition and extinction of somatic symptoms triggered by odours.

Methods-Diluted ammonia and butyric acid were odorous conditioned stimuli (CS). The unconditioned stimulus (US) was $7.4 \% \mathrm{CO}_{2}$ enriched air. One odour (CS+) was presented together with the US for 2 minutes (CS+ trial), and the other odour (CS-) was presented with air (CS-trial). Three CS+ and three CSexposures were run in a semi-randomised order; this as the acquisition (conditioning) phase. To test the effect of the conditioning, each subject then had one $\mathrm{CS}+o n l y$-that is, $\mathrm{CS}+$ without $\mathrm{CO}_{2}$-and one CS- test exposure. Next, half the subjects $(n=32)$ received five additional CS+only exposures (extinction group), while the other half received five exposures to breathing air (wait group). Finally, all subjects got one CS+only test exposure to test the effect of the extinction. Ventilatory responses were measured during and somatic symptoms after each exposure.

Results-More symptoms were reported upon exposure to CS+only than to CSodours, regardless of the odour type. Altered respiratory rate was only found when ammonia was $\mathrm{CS}+$. Five extinction trials were sufficient to reduce the level of acquired symptoms.

Conclusion-Subjects can acquire somatic symptoms and altered respiratory behaviour in response to harmless, but odorous chemical substances, if these odours have been associated with a physiological challenge that originally had caused these symptoms. The conditioned symptoms can subsequently be reduced in an extinction procedure. The study further supports the plausibility of a pavlovian conditioning hypothesis to explain the pathogenesis of MCS.

(Occup Environ Med 1999;56:295-301)
\end{abstract}

Department of Psychology O Van den Bergh K Stegen

I Van Diest

C Raes

P Stulens

P Eelen

Department of Occupational Medicine H Veulemans

Department of Pneumology,

University of Leuven, Belgium

K P Van de Woestijne

B Nemery

Correspondence to: Dr Omer Van den Bergh, Department of Psychology, Tiensestraat 102, B-3000 Leuven, Belgium.

Accepted 30 November 1998
Keywords: multiple chemical sensitivity; odours; pavlovian conditioning; extinction; $\mathrm{CO}_{2}$ inhalation
Multiple chemical sensitivity or idiopathic environmental intolerance ${ }^{1}$ refers to a poorly understood and controversial syndrome. ${ }^{2-4}$ Common symptoms include fatigue, difficulty concentrating, pounding heart, shortness of breath, anxiety, headache, and muscle tension. ${ }^{5}$ They occur "in response to demonstrable exposure to many chemically unrelated compounds at doses far below those established in the general population to cause harmful effects. No single widely accepted test of physiological function can be shown to correlate with symptoms". ${ }^{6}$ A recent World Health Organisation expert workshop report concluded that "human research is urgently needed to determine the nature - for example, psychogenic or toxicogenic - of multiple chemical sensitivity as the outcome will influence public policy and clinical practice for prevention and treatment of multiple chemical sensitivity respectively". ${ }^{1}$ Several theories of pathogenesis have been suggested, but there is no agreement on any specific mechanism. Pavlovian conditioning has been advanced as a possible explanation ${ }^{7-10}$ : odours may become conditioned stimuli (CSs), when experienced in association with acute overexposures to irritants or other aversive events as unconditioned stimuli (USs). However, most of the evidence for this view relies on case reports and uncontrolled studies ${ }^{9}$ and the explanation is not accepted by many researchers.

To test the plausibility of a pavlovian model of multiple chemical sensitivity, we developed a paradigm (experimental model) of differential odour conditioning (table 1 explains the technical terms of pavlovian conditioning).

In a learning (aquisition) phase, a subject inhaled an odour (which was to be the conditioned stimulus (CS+)) mixed with the US (7.4\% $\mathrm{CO}_{2}$ enriched air) in a 2 minute exposure. Another odour (which was not to be the conditioned stimulus (CS-)) was mixed with breathing air and served as a control. Each subject underwent three exposures of each type, in a semi-randomised order. In half the subjects ammonia was the CS+, and in the other half butyric acid was the CS+.

In the test phase, the same set of exposures was administered except that no $\mathrm{CO}_{2}$ was given with the CS+ (CS+only). Respiratory responses were measured during and symptoms were assessed after each exposure.

In a series of experiments with ammonia or niaouli (a mixture of volatile oils, containing $65 \%$ eucalyptus oil) as odours, we have 
Table 1. Explanation of some technical terms in a paradigm (experimental model) of pavlovian conditioning

\begin{tabular}{ll}
\hline Term & Meaning \\
\hline US, unconditioned stimulus & $\begin{array}{l}\text { A stimulus evoking a response by itself. In the present case } \\
7.4 \% \mathrm{CO}_{2} \\
\text { The palette of responses evoked by the US: in the present case, } \\
\text { the responses evoked by } 7.4 \% \mathrm{CO}_{2} \\
\text { A stimulus presented together with the US: in the present case, } \\
\text { an odour } \\
\text { A control stimulus in a differential conditioning paradigm: in } \\
\text { the present case, another odour presented with regular air } \\
\text { The responses elicited by the CS+ that are due to the } \\
\text { conditioning experiences } \\
\text { The CS+ presented without the US: after conditioning, it } \\
\text { regularly produces extinction, that is, a decrease of the learned } \\
\text { response } \\
\text { Awareness of the co-occurrence of the specific CS and US } \\
\text { The effects of the odours themselves, before using them as CSs }\end{array}$ \\
CS+ only &
\end{tabular}

previously shown that the breathing pattern was altered and that symptoms, mimicking the unconditioned responses (URs), occurred when subjects were exposed to the CS+only. ${ }^{11-13}$ Such effects were not found in response to new odours (odours that had not been presented with the US in the acquisition phase-for example the CS-) and they could not be attributed to different effects of the odours themselves, before conditioning. Interestingly, the learning effects occurred only with foul smelling ammonia and not with the neutral positive smelling niaouli as the CS+. Nevertheless, during the acquisition phase, conscious awareness among the subjects of the connection between the CS+ and the US was roughly equal for both odours, suggesting the involvement of more basic learning processes than those reflected by conscious cognition.

These experiments show that multiple chemical sensitivity might be at least partly explained by pavlovian conditioning: subjects can learn to experience specific symptoms and alter their breathing pattern in response to harmless chemical substances, if these have been associated with a physiological challenge that originally had caused these symptoms.

The present study had two aims. A first objective was to investigate extinction of the learned responses. A pavlovian extinction procedure involves repeated presentations of the conditioned stimulus alone (CS+only). The nature of extinction and the conditions in which it occurs are still a matter of debate. In signal learning paradigms (type "tone followed by shock", in which an organism learns to anticipate a here and now biologically important stimulus), an extinction procedure typically produces a decline in the learned response. In evaluative conditioning paradigms (type "neutral face followed by disliked face" in which an organism learns an evaluative response to a previously neutral stimulus without necessarily anticipating an imminent biologically important US), often no decline occurs in the learned response. ${ }^{14}$ These different effects of extinction procedures in pavlovian learning paradigms have been interpreted as reflecting qualitatively different functional learning systems: an expectancy system (the CS announces the imminent US) and a referential system (the CS refers to the US, without implying its imminent occurrence). ${ }^{14}$ The issue has poten- tial relevance for treatment for multiple chemical sensitivity. However, it is presently not clear whether extinction occurs in the present paradigm, and/or whether dissociations in this respect would occur among subjective rating of symptoms, respiratory responses, and ratings of pleasantness of the odours.

A second aim was to clarify why respiratory responses and somatic symptoms became conditioned to ammonia and not to niaouli in our previous studies. ${ }^{11-13}$ It is conceivable that an association between ammonia and $\mathrm{CO}_{2}$ was facilitated by (a) physiological similarity (irritant properties of ammonia and $\mathrm{CO}_{2}$, although both were presented at concentrations below the irritancy threshold); (b) affective similarity (sensing foul smelling ammonia and inhaling $\mathrm{CO}_{2}$ are both equally unpleasant experiences) ${ }^{15}$; (c) differences in salience (attracting attention) of the odours or habituation rates of the odours. In the present study, we therefore used ammonia as an irritant odour and butyric acid as a pure odour, both being equally unpleasant, salient, and with similar habituation rates.

\section{Participants and methods}

PARTICIPANTS

Sixty four healthy students (16 men, 48 women, aged 19-24 years) volunteered to participate in the study. They were paid $400 \mathrm{BEF}$ $(\$ 12, £ 6.50)$. A brief health inquiry checked for the presence of epilepsy, cardiac and respiratory diseases, panic disorder, or for medication being taken that may indicate presence of any of these disorders. Seventy one subjects had been invited, seven of them were excluded. The study was approved by an ethics committee.

Measured end points and methods were the same as in previous studies. ${ }^{12}{ }^{13}$ Only the important and the new features are summarised here.

\section{SUBJECTIVE END POINTS}

Symptoms were measured with the same list of 16 items used in our previous studies (table 2). ${ }^{11-13}$ For each item, the subject indicated whether they had experienced this symptom (not at all, slightly, medium, strongly, and very strongly, coded as $1,2,3,4$, and 5, respectively). The total sum was treated as a continuous variable. The following subsets were analysed separately ${ }^{16}$ : (a) general arousal, (b) respiration, (c) cardiac or warmth, (d) tingling sensation, and (e) unclassified. Also, we added a set of dummy symptoms, that are usually not provoked by breathing $\mathrm{CO}_{2}$ enriched air.

\section{CHEMICALS AND APPARATUS}

Butyric acid $(100 \%)$ and an aqueous solution of ammonia $(0.4 \%)$ were made into aerosols, with a Devilbiss Nebulizer 646, at a constant rate of $50 \mathrm{l} / \mathrm{h}$. The ammonia concentration was 5-6 ppm, which is far below the current threshold limit values (short term exposure limit (STEL)) of $35 \mathrm{ppm}$ based on irritancy (American Conference of Governmental Industrial Hygienists). 
Table 2 Subjective symptoms during the acquisition phase (across three trials) and during the test of conditioning for the $C S+$ and the $C S$ - trials as a function of the type of CS+ odour

\begin{tabular}{|c|c|c|c|c|c|c|c|c|}
\hline & \multicolumn{4}{|c|}{ Acquisition } & \multicolumn{4}{|l|}{ Test } \\
\hline & \multicolumn{2}{|c|}{ Ammonia CS+ } & \multicolumn{2}{|c|}{ Butyric acid CS+ } & \multicolumn{2}{|c|}{ Ammonia CS+ } & \multicolumn{2}{|c|}{ Butyric acid CS+ } \\
\hline & CS+ & $C S_{-}$ & CS+ & $C S_{-}$ & $C S+$ & $C S_{-}$ & $C S+$ & $C S_{-}$ \\
\hline Arousal & 7.0 & 3.6 & 6.4 & $3.8^{\star \star \star}$ & 3.4 & 3.1 & 3.5 & 3.4 \\
\hline Respiration & 11.6 & 5.3 & 10.7 & $5.2^{\star \star \star}$ & 5.1 & 4.3 & 5.3 & $4.7^{\star \star \star}$ \\
\hline Cardiac, warmth & 6.7 & 3.6 & 6.7 & $3.7^{\star \star \star}$ & 3.8 & 3.6 & 3.5 & 3.4 \\
\hline Tingling sensations & 2.6 & 2.2 & 2.5 & $2.1^{\star \star}$ & 2.3 & 2.9 & 2.1 & 2.1 \\
\hline Unclassified & 6.9 & 5.0 & 6.3 & $4.6^{\star \star \star}$ & 5.1 & 4.7 & 4.8 & $4.5^{\star \star}$ \\
\hline Total symptom score & 34.9 & 19.8 & 32.6 & $19.5^{\star \star \star}$ & 19.6 & 17.9 & 19.2 & $18.1^{\star \star \star}$ \\
\hline Dummy & 5.8 & 5.6 & 5.5 & 5.6 & 5.8 & 5.9 & 5.7 & 5.6 \\
\hline
\end{tabular}

${ }^{\star \star} \mathrm{p}<0.01 ;{ }^{\star \star \star} \mathrm{p}<0.001$; for the $\mathrm{CS}+/ \mathrm{CS}-$ difference across the two types of CS+ odours.

Arousal=tension, anxious feelings, feelings of panic; respiration=fast breathing, smothering sensations, chest tightness, feelings of choking; cardiac, warmth=pounding heart, sweathing, hot flushes; tingling sensations=tingling or numbness in extremities, in face; unclassified=lump in throat, headache, dizziness, cold chills; dummy=joint pain, sleepy feeling, low back pain, blocked nose, burning eyes.

After extensive earlier piloting with several odours at different concentrations, nine volunteers rated both the odours that we used, administered in 2 minute exposures, for pleasantness (affectiveness valence) (very good $(+5)$, very bad $(-5)$ ), salience (0 (attracting no attention) to 10 (very salient)), and duration of perception (on a $10 \mathrm{~cm}$ line, representing the 2 minutes). Ammonia and butyric acid were rated, respectively, -3.0 and -2.8 for pleasantness, 7.8 and 7.0 for detectibility, and $9.2 \mathrm{~cm}$ and $8.2 \mathrm{~cm}$ for duration. Also, after each exposure the check list of symptoms (already mentioned) was assessed. The two odours were not significantly different for any of these measures.

The $\mathrm{CO}_{2}$ enriched air mixture consisted of $7.4 \% \mathrm{CO}_{2}, 21 \% \mathrm{O}_{2}$, and $71.6 \% \mathrm{~N}_{2}$, the placebo mixture was compressed breathing air $(21 \%$ $\mathrm{O}_{2}, 79 \% \mathrm{~N}_{2}$ ). After decompression, the gases were led through wide vinyl tubes to a double one way valve, which separated inspired and expired air. That was connected through a pneumotachograph (Fleisch No 2, Switzerland) to a tightly fitting mask enclosing mouth and nose. The odours were fed into the connection between the pneumotachograph and the mask. A three way stopcock could be switched to feed either the normal air or the $\mathrm{CO}_{2}$ mixture into the tube without the subject being aware of this. An infrared $\mathrm{CO}_{2}$ monitor (Poet RC, Criticare, USA) was connected close to the mask and sampled inspired and expired air. Airflow and $\mathrm{CO}_{2}$ waveforms were sampled at a rate of $20 \mathrm{~Hz}$ and stored on a personal computer. Off line, a software program $^{17}$ counted and removed pauses and irregularities from the datafile and subsequently extracted the following primary variables per breathing cycle: inspiratory time ( $\mathrm{Ti}$ ) and expiratory time $(\mathrm{Te})$, inspiratory volume (Vi) and expiratory volume (Ve), and end tidal fractional concentration of $\mathrm{CO}_{2}\left(\mathrm{FETCO}_{2}\right)$.

PROCEDURE

On arrival in the laboratory, the participants answered the general health questions. Then, they were told (a) that the experiment aimed at testing respiratory behaviour while breathing different innocuous gases; (b) that minor symptoms such as a little dizziness, headache, and shortness of breath could occur with some of these gases, but they would disappear quickly; (c) that they were allowed to stop the experiment at any moment. After signing the informed consent form, the subject was told that the experiment consisted of two blocks of breathing trials of 2 minutes each, followed by the symptom list to check how they felt after breathing the specific gas. The sequence of trials is depicted in figure 1 .

A pause of 30 minutes separated the acquisition and test phases. Immediately after each phase, subjects rated odours for pleasantness and salience. To test whether participants were aware of the association between CS+ and US they were given a puff of each odour. After each puff, they rated the pleasantness of the odour on a scale of -5 to +5 and they indicated for which of the two odours they had felt most symptoms (CS+, CS-, or don't know, scored as $1,-1$, and 0 , respectively).

\section{DESIGN AND DATA ANALYSIS}

Statistical analyses were run on means for respiratory rate $(\mathrm{f})$, minute ventilation $\left(\mathrm{V}_{\mathrm{E}}=\mathrm{V}_{\mathrm{T}} \mathrm{xf}\right)$, and $\mathrm{FETCO}_{2}$. (Because Vi and Ve were equal, only $\mathrm{Vi}$ was used in the analyses and was termed $\mathrm{V}_{\mathrm{T}}$.) Analyses of the symptoms were run on the total score, and on the various subsets. The context exposure data of each phase served as respective covariates for acquisition and test analyses of covariance (ANCOVAs).

The conditioning effect on symptoms was analysed in a design with CS+ odour (ammonia or butyric acid) and conditioning (CS+ or CS-) as variables among which the CS+ odour was a between subject variable and conditioning was a within subject variable. The extinction effect was analysed in a design by group (extinction or wait), CS+ odour, and trial (first CS+only and last CS+only). The trial was a within subject repeated measure variable. The ANCOVAs on the symptoms during acquisition had gas mixture $\left(\mathrm{CO}_{2} /\right.$ air $)$ and $\mathrm{CS}+$ type $\mathrm{x}$ exposure (first, second, third) as variables. Greenhouse-Geisser corrections for heterogeneity of variances and covariances in a repeated measures design were used when appropriate.

Unconditioned odour effects were tested in the 32 subjects, that started the acquisition phase with a CS- exposure in an ANOVA with the variables CS+ odour and type of trial (context trial, first CS- trial). If the two odours 


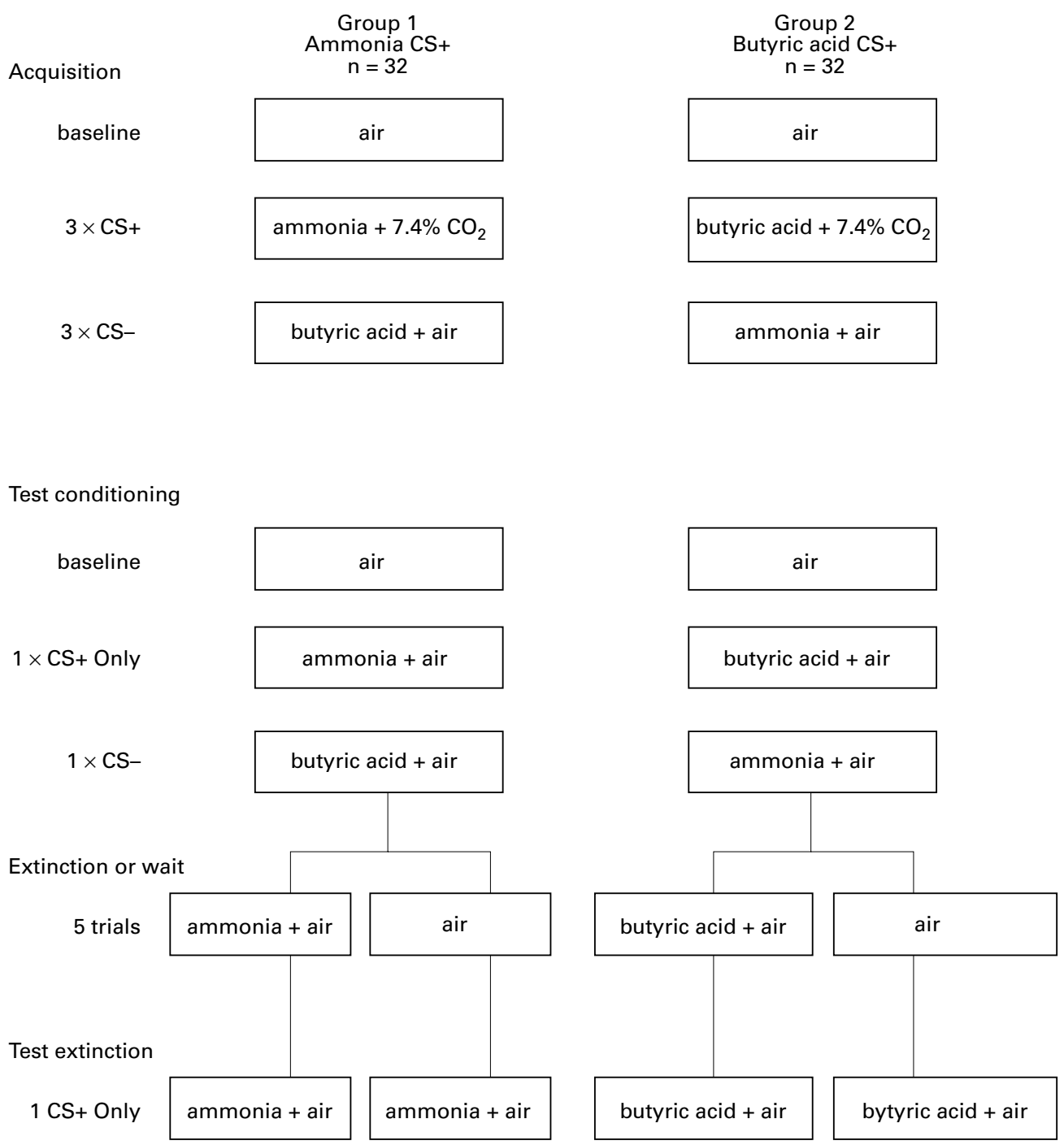

Figure 1 Experimental design. The order of the 2 minute exposures within a group was semi-randomised in the following way. Acquisition: baseline exposure; exposures 2 and $3=C S+$ and $C S-$ for half the subjects, the reversed order for the other half; exposures 4-7 2 CS+ and 2 CS-, no more than 2 exposures of the same type were allowed. Test of conditioning: baseline exposure; exposures 2 and $3=$ half the subjects who had a CS+ then CS-during acquisition had the same order during the test, the other half had the order reversed. This amounted to eight possible orders per CS+ type, or 16 different trial patterns in total. There were four subjects per trial pattern. Two of these were randomly allocated to the extinction group $(n=16)$, receiving $5 C S+o n l y$ exposures and a final CS+only test exposure. The other two, allocated to the wait group ( $n=16)$, received 5 exposures to air and a final CS+only test exposure.

evoked different responses before using them as CS, this would show up as an interaction between CS+ odour and type of trial interaction.

For the respiratory measures, a within subject block variable (1st or 2 nd minute) was added to each of these designs.

\section{Results}

UNCONDITIONED EFFECTS OF ODOUR

Adding an odour to breathing air increased the level of symptoms $(p<0.02$ for the total score, and $p \leqslant 0.05$ for each of the respiratory, tingling, unclassified, and dummy sets). Minute ventilation tended to decrease in the second odorous exposure $(\mathrm{p}=0.05)$. However, all these effects were the same for both odours, thus indicating that there were no pre-existing differences between them before using them in the conditioning phase.
ACQUISITION

As expected, inhaling $\mathrm{CO}_{2}$ had strong effects on the level of reported symptoms (table 2) as well as on the breathing pattern (table 3 ). Interactions were not found between the US and the type of odour used as CS+. This also indicated an absence of unconditioned differences between the odours.

\section{TEST OF CONDITIONING}

Subjective symptoms

Table 2 shows that the subjects had learned to experience symptoms: they reported more symptoms to the conditioned odour than to the control odour (CS+only compared with CS- in the test phase: $F(1,61)=14.80, \mathrm{p}<0.001)$ and this effect was similar for both ammonia and butyric acid as $\mathrm{CS}+(F<1$ for the interaction). The learning effect was significant for the respiratory $(F(1,61)=17.70, \mathrm{p}<0.001)$, and the unclassified set of data $(F(1,61)=8.33$, 
Table 3 Respiratory responses during the acquisition phase (across three trials) and during the conditioning test for the $C S+$ and the $C S-$ trials as a function of the type of $C S+$ odour

\begin{tabular}{|c|c|c|c|c|c|c|c|c|}
\hline & \multicolumn{4}{|c|}{ Acquisition } & \multicolumn{4}{|l|}{ Test } \\
\hline & \multicolumn{2}{|c|}{ Ammonia CS+ } & \multicolumn{2}{|c|}{ Butyric acid CS+ } & \multicolumn{2}{|c|}{ Ammonia CS+ } & \multicolumn{2}{|c|}{ Butyric acid CS+ } \\
\hline & CS+ & $C S_{-}$ & CS+ & $C S-$ & CS+ & $C S_{-}$ & CS+ & $C S_{-}$ \\
\hline Respiratory rate $(\mathrm{f} / \mathrm{min})$ & 16.2 & 14.8 & 17.7 & $16.1^{\star \star \star}$ & 15.5 & $14.3^{\star}$ & 16.2 & 16.3 \\
\hline Ventilation $(1 / \mathrm{min})$ & 16.3 & 8.9 & 14.9 & $8.1^{\star \star \star}$ & 8.6 & 8.3 & 8.3 & 8.3 \\
\hline $\mathrm{FETCO}_{2}(\%)$ & 7.2 & 5.0 & 7.1 & $5.1^{\star \star \star}$ & 5.1 & 5.0 & 5.2 & 5.2 \\
\hline
\end{tabular}

${ }^{\star} \mathrm{p}<0.05(\mathrm{CS}+/ \mathrm{CS}-$ difference for ammonia $\mathrm{CS}+) ;{ }^{\star \star \star} \mathrm{p}<0.001$ for the $\mathrm{CS}+/ \mathrm{CS}-$ difference across the two types of CS+ odours.

$\mathrm{FETCO}_{2}=$ end tidal fractional concentration of $\mathrm{CO}_{2}$.

$\mathrm{p}<0.01$ ), and marginally for the arousal $(\mathrm{p}=0.15)$ and the cardiac or warmth data $(\mathrm{p}=0.11)$.

\section{Respiratory measures}

Table 3 shows that the subjects had learned to breathe faster during CS+only exposure, but only when ammonia had been the CS+ (15.5v 14.3: $F(1,61)=4.36, \mathrm{p}<0.05$; for butyric acid as $\mathrm{CS}+16.2$ v 16.3, $F<1$; interaction between CS+ odour and conditioning: $F(1,61)=2.43$, $\mathrm{p}=0.12)$. No other significant effects emerged.

\section{TEST OF EXTINCTION}

Subjective symptoms

Figure 2 shows that the extinction procedure reduced the level of conditioned symptoms on the last CS+only exposure compared with the first $(F(1,59)=6.75, \mathrm{p}<0.02$; group $\mathrm{x}$ trial $F(1,59)=7.44, \mathrm{p}<0.01)$. This pattern was most pronounced in the respiratory and the unclassified set (group $\mathrm{x}$ trial, respiratory set $F(1,59)=6.51, \quad \mathrm{p}<0.02$; unclassified set $F(1,59)=4.13, \mathrm{p}<0.05)$.

\section{Respiratory measures}

No significant extinction effects were found for any of the respiratory variables. This is most likely due to the weak conditioning effects on respiratory responses.

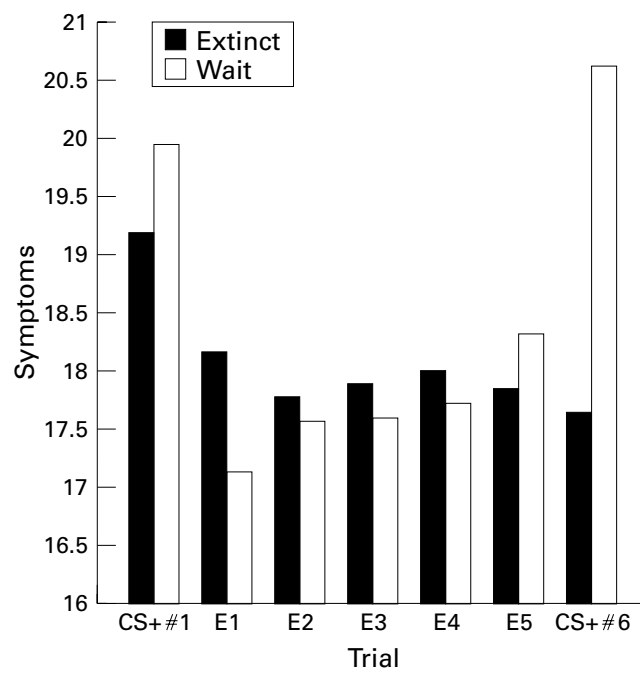

Figure 2 Level of symptoms in the extinction and wait groups. CS+1 was the first conditioning test exposure (CS+only). It was followed by five additional CS+only exposures in the extinction group and by five exposures to air in the wait group (E1 to E5). CS+6 refers to the final exposure to the CS+only for all subjects.
PLEASANTNESS AND SALIENCE

The main findings were that, for both odours, the CS+ odour was rated more negatively (less pleasant) than the CS-, but it became less negative after the test phase (phase $\mathrm{x} C S+$ or CS- $F(1,56)=4.27, \mathrm{p}<0.05)$. Across both phases, butyric acid became more negative as a $\mathrm{CS}+$ and less negative as a CS- than ammonia $((\mathrm{CS}+$ odour $) \times(\mathrm{CS}+, \mathrm{CS}-) F(1,56)=4.49$, $\mathrm{p}<0.05)$.

Twenty three subjects in whom ammonia was the CS+ said that the odour that produced most symptoms was ammonia, and nine said butyric acid. With butyric acid as the CS+, 27 said that the odour that produced most symptoms was butyric acid, four said ammonia, and one did not know.

\section{Discussion}

The present experiment showed that after three respiratory challenges associated with an odour, that odour alone was able to elicit somatic symptoms. The effect was modest in size, but highly reliable. The low intensity of the present symptoms induced in the laboratory in well informed and consenting subjects fortunately (but intentionally) bears no resemblance to accidental exposures in real life or to the experience of - for example, acute unexplained hyperventilation. Highly unexpected and strongly aversive events - such as the US-generally cause stronger responses than the conditioned stimulus.

Conditioned symptoms occurred with both types of odour, showing that irritancy does not explain why, in our previous studies, subjects learned to have symptoms to foul smelling ammonia, but not to neutral positively smelling niaouli. A more likely explanation is the difference in the pleasantness of the smell. Indeed, in a recent study we used mental images with either a negative (imagining being stuck in a lift) or a neutral positive idea (reading a book in one's living room) as CSs in a similar conditioning example with $\mathrm{CO}_{2}$ inhalation. Increased symptoms and altered respiratory behaviour were only found to negative and not to neutral positive CS+only images. ${ }^{18}$ However, no difference was found in the ability to identify consciously which image had been associated with the respiratory challenge during acquisition. Because awareness of the conditioned or unconditioned state was not sufficient to cause conditioning effects, more basic learning processes than those reflected by aware cognition are likely to be involved in our paradigm. 
However, to condition the breathing pattern, irritancy did seem to matter, because frequency of breathing only increased with conditioning to ammonia as the CS+. This suggests a dissociation between the critical conditions for learning symptoms, on the one hand, and physiological responses, on the other. Also, it suggests that the conditioned symptoms, among which respiratory symptoms were prominent, did not simply reflect the conditioned respiratory behaviour. This is in line with other findings of our group ${ }^{13}$ showing that the learned symptoms were based on the activation of information in memory about the subjective experiences during the acquisition phase, and were not based on an accurate perception of learned respiratory responses during the test phase.

The present results showed also that learned symptoms can be reduced in a typical pavlovian extinction paradigm. Also the evaluative responses (ratings of pleasantness) to the odours can be extinguished, suggesting that both subjective symptoms and ratings of pleasantness behave as an example of typical signal learning. The finding that behaviour treatments-such as systematic desensitisation-seem to be helpful is consistent with a learning account of multiple chemical sensitivity. ${ }^{919}$ All this confirms the validity of the hypothesis of odour conditioning as a mechanism for the pathogenesis of multiple chemical sensitivity.

However, several objections have been made against this hypothesis. Firstly, traumatic toxic exposures to odorous substances as USs are not found in all patients with multiple chemical sensitivity. ${ }^{3}$ However, some authors have pointed to the potential involvement of hyperventilation to explain symptoms related to multiple chemical sensitivity.${ }^{72}{ }^{20}$ We hypothesise that regular episodes of hyperventilation in association with an odour, producing unexplained symptoms similar to those induced by $\mathrm{CO}_{2}$, may function as learning trials in the same way as shown here. This would explain the substantial overlap between the symptoms, and the elusive character, of both multiple chemical sensitivity and the so called hyperventilation syndrome. Indeed, our findings may also explain why in the hyperventilation syndrome typical symptoms may be found in the absence of concurrent hypocapnia. ${ }^{21}$

A second objection is that patients with multiple chemical sensitivity often report symptoms to substances without distinctive odours. However, as already noted, even mental images experienced in association with a minor respiratory challenge have been shown to function in the same way as conditioned stimuli to odours. So, it is likely that other stimuli without a distinctive odour (food, medications, places, or particular mental cues) may become able to elicit somatic symptoms.

Thirdly, because of the rapid extinction found here, why might multiple chemical sensitivity actually persist in clinical cases, despite frequent re-exposures? Two mechanisms may account for this. Firstly, a retarded extinction or even paradoxical increase in learned responses to unreinforced conditioned stimuli have been documented with very intense unconditioned stimuli or with highly neurotic subjects. (It may be of potential clinical importance to note that the level of symptoms tended to rise between the first and second exposure to the CS+only odour after only a 15 minute waiting period. Incubation effects, showing a substantial increase of the learned response caused by the mere passage of more time between acquisition and test, have been reported in publications of pavlovian conditioning. $)^{22}{ }^{24}$ Secondly, as hyperventilation is a function of the UC, it seems that each new episode of hyperventilation, potentially induced by anticipatory stress will reinforce the existing association and prevent effective extinction.

In conclusion, subjects can acquire specific symptoms and altered respiratory behaviour in response to harmless odours, if these have been associated with a physiological challenge that originally had caused the effects. Also, the symptoms can be reduced by extinction. The study further supports a possible pavlovian perspective for the pathogenesis in multiple chemical sensitivity, and this may provide valuable hypotheses that could be tested in clinical studies. Furthermore, the relevance of our findings may go beyond multiple chemical sensitivity by offering a paradigm to study the dynamic relation between health symptoms and physiological responses in many respiratory and other diseases.

The study was supported by the Research Council of the University of Leuven (OT-97/16) and the Fund for Scientific Research - Flanders (FWO G.0399.98).

1 International programme on chemical safety. Conclusions and recommendations of a workshop on multiple chemical sensitivities (MCS). Int Arch Occup Environ Health 1997;69:224-6.

2 Fiedler N, Kipen HM, eds. Experimental approaches to chemical sensitivity. Environ Health Perspect 1997; 105 (suppl 2).

3 Ziem GE, Davidoff LL. Illness from chemical "odors: is the Ziem GE, Davidoff LL. Illness from chemical "odors: is the
health significance understood. Arch Environ Health 1992;47:88-91.

4 Special issue. Proceedings of the conference on low-level exposure to chemicals and neurobiological sensitivity. Toxicol Ind Health 1994;10.

5 Miller CS. Chemical sensitivity: history and phenomenology. Toxicol Ind Health 1994;10:253-76.

6 Cullen MR. The worker with multiple chemical hypersensitivities: an overview. Occup Med 1987;2:655-61.

7 Shusterman DJ. Critical review: the health significance of environmental odor pollution. Arch Environ Health 1992; 47:76-87.

8 Sparks PJ, Daniell W, Black DW, et al. Multiple chemical sensitivity syndrome: a clinical perspective. II Evaluation, diagnostic testing, treatment, and social considerations. $\mathcal{f}$ Occup Med 1994;36:731-7.

9 Bolla-Wilson K, Wilson RJ, Bleecker ML. Conditioning of physical symptoms after neurotoxic exposure. 7 Occup Med 1988;30:684-6.

10 Siegel S, Kreutzer, R. Pavlovian conditioning and multiple chemical Sensitivity. Environ Health Perspect 1997; 105(suppl):521-6.

11 Van den Bergh O, Kempynck PJ, Van de Woestijne KP, et al. Respiratory learning and somatic complaints: a conditioning approach using $\mathrm{CO}_{2}$-enriched air inhalation. Behav Res Ther 1995;5:517-27.

12 Van den Bergh O, Stegen K, Van de Woestijne KP. Learning to have psychosomatic complaints: conditioning of respiratory behavior and somatic complaints in psychosomatic patients. Psychosom Med 1997;59:13-23.

13 Van den Bergh O, Stegen K, Van de Woestijne KP. Memory effects on symptom reporting in a respiratory learning paradigm. Health Psychol 1998;17:241-8.

14 Baeyens F, Eelen P, Crombez G. Pavlovian associations are forever: on classical conditioning and extinction. F Psychophys 1995;9:127-41.

15 Hamm AO, Vaitl D, Lang PJ. Fear conditioning, meaning and belongingness: a selective association analysis. $\mathcal{f}$ abnorm Psychol 1989;98:395-406.

16 Wientjes CJE, Grossman P. Overreactivity of the psyche or the soma? Interindividual associations between psychoso- 
matic symptoms, anxiety, heart rate, and end-tidal partial matic symptoms, anxiety, heart rate, and end-tidal partial carbon dioxide pressure. Psychosom Med 1994;56:533-40.
17 Han JN. Breathing patterns in anxiety disorders: is there a hyperventilation syndrome? [Doctoral dissertation]. Leuven: hyperventilation syndrome? [Doctor

18 Stegen K, De Bruyne K, Rasschaert W, et al. Fear-relevant mental images as conditioned stimuli for subjective symptoms, respiratory behavior and end-tidal $\mathrm{pCO}_{2}$. 7 Abnorm Psychol (in press).

19 Guglielmi, RS, Cox DJ, Spyker DA. Behavioral treatment of phobic avoidance in multiple chemical sensitivity. F Behav Ther Exp Psychiatry 1994;25:197-209.

20 Lehrer PM. Psychophysiological hypotheses regarding multiple chemical sensitivity syndrome. Environ Health Perspect 1997:105(suppl 2):479-84.
21 Hornsveld H, Garssen B, Fiedeldij Dop MF, et al. Doubleblind placebo-controlled study of the hyperventilation
provocation test and the validity of the hyperventilation syndrome. Lancet 1996;348:154-8

22 Jacobs WJ, Blackburn JR. Factors contributing to the magnitude of conditional fear following a 24-h retention interval: the incubation effect. Bull Psychonomic Soc 1988;26:145-8.

23 Eysenck HJ. The conditioning model of neurosis. Behav Brain Sci 1979;2:155-66.

24 Mineka S, Zinbarg R. Conditioning and ethological models of anxiety disorders: stress-in-dynamic-context anxiety models. In: Hope DA, ed. Perspectives on anxiety, panic, and fear. Nebraska Symposium on Motivation. (Vol 43). Lincoln : University of Nebraska Press. 1996:135-210.

\section{Occupational and Environmental Medicine - http://www.occenvmed.com}

Visitors to the world wide web can now access Occupational and Environmental Medicine either through the BMJ Publishing Group's home page (http://www.bmjpg.com) or directly by using its individual URL (http://www.occenvmed.com). There they will find the following:

- Current contents list for the journal

- Contents lists of previous issues

- Members of the editorial board

- Subscribers' information

- Instructions for authors

- Details of reprint services.

A hotlink gives access to:

- BMJ Publishing Group home page

- British Medical Association website

- Online books catalogue

- BMJ Publishing Group books.

The web site is at a preliminary stage and there are plans to develop it into a more sophisticated site. Suggestions from visitors about features they would like to see are welcomed. They can be left via the opening page of the BMJ Publishing Group site or, alternatively, via the journal page, through "about this site". 